reported in our cohort of JIA patients. At the time of COVID-19 diagnosis, nearly $80 \%$ of patients in our cohort had been treated with conventional DMARD and/ or biologics. This seemed not to have a negative effect on severity or outcome of SARS-CoV2 infection.

Acknowledgements: Thanks also for contributing Reports for this analysis to: Normi Brück, Frank Dressler, Ivan Foeldvari, Tilman Geikowski, Hermann Girschick, Johannes-Peter Haas, Tilmann Kallinich, Bernd-Ulrich Keck, Eggert Lilienthal, Anna-Hedrich Müller, Ulrich Neudorf, Nils Onken, Peggy Rühmer.

Disclosure of Interests: None declared.

DOI: 10.1136/annrheumdis-2021-eular.2045

\section{POS1203 EFFECT OF THE COVID19 PANDEMIC ON RHEUMATOLOGIST PRESCRIPTION BEHAVIOUR OF NEW ADVANCED THERAPY: DATA OF THE TARDIS-RA REGISTRY, A NATIONWIDE BELGIAN BIOLOGIC REGISTRY}

D. De Cock ${ }^{1}$, P. Durez ${ }^{2}$, V. Badot ${ }^{3}$, R. Westhovens ${ }^{1,4}$, P. Verschueren ${ }^{1,4} .{ }^{1} K U$ Leuven, Skeletal Biology and Engineering Research Centre, Leuven, Belgium; ${ }^{2}$ Cliniques universitaires Saint-Luc, Rheumatology, Brussels, Belgium; ${ }^{3} \mathrm{CHU}$ UVC Brugmann, Division of Rheumatology, Brussels, Belgium; ${ }^{4}$ University Hospitals Leuven, Rheumatology, Leuven, Belgium

Background: Belgium suffered considerably from the COVID19 pandemic with high hospitalisation rates during 2 periods: a first wave in March and April 2020, and a second starting from October until the end of 2020. Measures of lowering social interaction were taken throughout 2020 and intensified during the first and second wave when needed. This pandemic could have influenced the access to care and advanced therapies for patients with Rheumatoid Arthritis (RA). In the electronic platform "Tool for Administrative Reimbursement Drug Information Sharing" (TARDIS), data from all Belgian RA patients on biologic and targeted therapy are collected during the submission of a request for initiation and prolongation of reimbursement for these drugs.

Objectives: to investigate the effect of the COVID19 pandemic on the monthly prescription behaviour of a new advanced therapy in 2020 by comparing it to 2019.

Methods: Patients were selected for this analysis if they started a new TNFi, $\mathrm{B} / \mathrm{T}$ cell therapy, IL6 inhibitors or tsDMARD therapy in the TARDIS registry in 2019 or in 2020. Rheumatologists request reimbursement via the online TARDIS tool, which is considered here as a new drug prescription. Prescription behaviour was compared between 2019 and 2020, between bionaive and bioexperienced patients, and between the different drug classes

Results: In 2019, 2949 patients were prescribed any new advanced therapy, including $1153 \mathrm{TNFi}, 469 \mathrm{~B} / \mathrm{T}$ cell therapy, 436 IL6 inhibitors and 891 tsDMARDs. In 2020, 2998 patients were prescribed any new advanced therapy including 1233 TNFi, 382 B/T cell therapy, 496 IL6 inhibitors and 887 tsDMARDs.

On a monthly basis, on average 246 and 250 new advanced therapies were prescribed in 2019 and 2020 respectively. Monthly deviations from this average in 2019 ranged from $-19 \%$ to $+16 \%$. Monthly deviations from this average in 2020 ranged from $-50 \%$ to $+30 \%$. Figure $1 \mathrm{~A}$ shows the monthly prescription of new advanced therapies in 2019 and 2020.
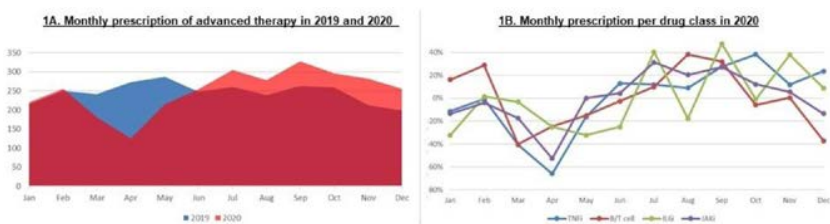

For bionaive and bioexperienced patients, the same trend can be noted. Monthly deviations in bionaive patients in 2020 ranged from $-60 \%$ to $+38 \%$, compared to $-18 \%$ to $+21 \%$ in 2019 . Monthly deviations in bioexperienced patients ranged from $-40 \%$ to $+25 \%$, compared to $-19 \%$ to $+17 \%$ in 2019 .

Comparison per drug class in 2020 show similar trends. IL6 inhibitors show a slightly different timeline than other drugs classes with other periods of less or more prescriptions changes compared to the other drugs classes. See Figure 1B.

Conclusion: The COVID19 pandemic did affect reimbursement requests for patients starting new advanced therapies in March and April 2020, especially for bionaive patients. The latter half of 2020 was apparently used to catch up with reimbursement requests for patients in need for advanced therapies resulting in similar total numbers of patients treated with advanced therapy in 2019 and 2020. The choice for a particular drug type was not clearly influenced by the pandemic. IL6 inhibitor use did seem to be affected differently by the pandemic, yet caution is warranted as these relatively large differences in proportional changes parallel small differences in actual drug numbers.
In sum, the observed effect of the pandemic on initiating advanced therapy during the first wave corresponds with Belgian governmental measures that restricted non-essential care which was less observed in the latter half of 2020.

Disclosure of Interests: None declared.

DOI: 10.1136/annrheumdis-2021-eular.2049

\section{\begin{tabular}{|l|l}
\hline POS1204 LOW POSITIVITY RATE IN ANTIBODY SARS-COV2 \\
\hline
\end{tabular} TESTS IN PATIENTS WITH RHEUMATIC DISEASES TREATED WITH RITUXIMAB. A CASE CONTROL STUDY OF A HIGH IMPACT SARS-COV2 INFECTION AREA.}

A. García Fernández ${ }^{1}$, P. Morán Álvarez ${ }^{1}$, J. Bachiller-Corral ${ }^{1}$, M. Vázquez Díaz ${ }^{1}{ }^{1}$ Hospital Universitario Ramón y Cajal, Rheumatology, Madrid, Spain

Background: Diagnosis of previous SARS-COV2 infection may be challenging in immunocompromised patients.

Objectives: To analyze positivity rate to SARS-COV2 antibody tests (SC2AT) in patients diagnosed of rheumatic diseases (RMD) treated with Rituximab.

Methods: We conducted a case-control study of patients diagnosed of RMD followed in a referral hospital in Madrid, Spain. Positivity rate to IgG-SC2AT were analyzed in Rituximab-treated patients (RTX) compared with patients treated with TNF inhibitors (TNFi) and/or conventional DMARDs (cDMARDs) (N-RTX).

We included patients that received Rituximab in the previous year to a confirmed SARS-COV2 infection (defined as a positive polymerase chain reaction test (PCR) and/or compatible chest Xray), to a suspected SARS-COV2 infection (2 or more symptoms) or to SC2AT determination. Patients with RMD treated with other biological DMARDs (bDMARDs) rather than Rituximab or TNFi were excluded.

Results: We included 152 patients with RMD who underwent a SC2AT. Main characteristics are reported in Table 1.

Table 1. Main characteristics. AS, axial spondylitis; bDMARDs, biological disease-modifying anti-rheumatic drugs; cDMARDs, conventional DMARDs; COPD, Chronic obstructive pulmonary disease; CVD, Cardiovascular disease; IMM, immune-mediated myositis; JIA, Juvenile Idiopathic arthritis; PsoA, Psoriatic Arthritis; RA, Rheumatoid Arthrtis; SLE, Systemic Lupus Erythematosus; SSc, Systemic Sclerosis; SSj, Sjogren Syndrome.

\begin{tabular}{|c|c|c|c|}
\hline & $\begin{array}{l}\text { Rituximab } \\
\text { (RTX) }\end{array}$ & $\begin{array}{l}\text { Non-Rituximab } \\
\quad(\mathrm{N}-\mathrm{RTX})\end{array}$ & $p$ value \\
\hline Patients, n (\%) & $48(31.6)$ & $104(68.4)$ & \\
\hline Age, years, median (IQR) & $65(54-72)$ & $60(47-71.8)$ & $p=0.190$ \\
\hline Female, $n(\%)$ & $38(79.2)$ & $74(71.2)$ & $\mathrm{p}=0.297$ \\
\hline Diagnosis, $\mathrm{n}(\%)$ & & & $\mathrm{p}=0.2$ \\
\hline$-\mathrm{RA}$ & $20(41.7)$ & $42(40.4)$ & \\
\hline$-S S j$ & $4(8.3)$ & $6(5.8)$ & \\
\hline - RA SSj & $3(6.3)$ & $0(0)$ & \\
\hline - SLE & $4(8.3)$ & $8(7.7)$ & \\
\hline - Vasculitis & $7(14.6)$ & $13(12.5)$ & \\
\hline - IMM & $1(2.1)$ & $4(3.8)$ & \\
\hline - JIA & $2(4.2)$ & $3(2.9)$ & \\
\hline - SSc & $7(14.6)$ & $15(14.4)$ & \\
\hline -AS & $0(0)$ & $4(3.8)$ & \\
\hline - PSoA & $0(0)$ & $5(4.8)$ & \\
\hline - Others ${ }^{a}$ & $0(0)$ & $4(3.8)$ & \\
\hline \multicolumn{4}{|l|}{ Comorbidities, n (\%) } \\
\hline - Hypertension & $18(37.5)$ & $34(32.7)$ & $\mathrm{p}=0.561$ \\
\hline - Diabetes & $5(10.4)$ & $10(9.6)$ & $p=0.878$ \\
\hline - Dyslipidemia & $18(37.5)$ & $30(28.8)$ & $\mathrm{p}=0.286$ \\
\hline - COPD/asthma & $6(12.5)$ & $4(3.8)$ & $\mathrm{p}=0.049^{*}$ \\
\hline - CVD & $11(35.4)$ & $25(24)$ & $\mathrm{p}=0.831$ \\
\hline Interstitial lung disease, $\mathbf{n}(\%)$ & $17(35.4)$ & $8(7.7)$ & $p<0.0001^{*}$ \\
\hline Corticosteroids use, n (\%) & $26(54.2)$ & $33(31.7)$ & $\mathrm{p}=0.008^{*}$ \\
\hline cDMARDs use, $\mathrm{n}(\%)$ & $27(56.3)$ & $73(70.2)$ & $\mathrm{p}=0.092$ \\
\hline bDMARDs, n (\%) & & & - \\
\hline - None & $0(0)$ & $83(79.8)$ & \\
\hline - TNF inhibitors & $0(0)$ & $21(20.2)$ & \\
\hline - Rituximab & $48(100)$ & $0(0)$ & \\
\hline Previous positive PCR, n (\%) & $8(16.7)$ & $20(19.2)$ & $\mathrm{p}=0.191$ \\
\hline $\begin{array}{l}\text { - Time from positive PCR to SC2AT, } \\
\text { days, mean } \pm \text { SD }\end{array}$ & $47.4(38.7)$ & $65.1(49)$ & $p=0.368$ \\
\hline \multicolumn{4}{|l|}{ Previous symptoms, n (\%) } \\
\hline - Time from symptom onset to SC2AT, & $13(27.1)$ & $36(34.6)$ & $\mathrm{p}=0.356$ \\
\hline days, mean $\pm S D$ & $130.3 \pm 91.1$ & $93.5 \pm 72.6$ & $p=0.15$ \\
\hline COVID, n (\%) & & & $\mathrm{p}=0.183$ \\
\hline - Non suspected & 35 (72.9) & $66(63.5)$ & \\
\hline - Suspected & $3(6.3)$ & $18(17.3)$ & \\
\hline - Confirmed & $10(20.8)^{b}$ & $20(19.2)$ & \\
\hline
\end{tabular}

${ }^{a}$ Including gout, polymyalgia rheumatica. ${ }^{\mathrm{b}}$ Two patients had negative PCR but compatible symptoms and chest X-Ray. 